\title{
Menarche's Experience in Adolescents: Scoping Review
}

\author{
Nahdiyatul Mukaromah ${ }^{1}$, Ismarwati $^{2}$ \\ ${ }^{1,2}$ Universitas 'Aisyiyah Yogyakarta, J1. Ringroad Barat No.63, Kec. Gamping, Kabupaten Sleman 55592, Daerah \\ Istimewa Yogyakarta \\ 1'nahdiyatulmukaromah@gmail.com*; ${ }^{2}$ ismarwari@unisayogya.ac.id \\ *corresponding author
}

Submission date: 16 Desember 2020, Receipt date: 24 Januari 2021, Publication date: 1 April 2021

\begin{abstract}
Menarche is a sign of physical maturity and fertility. The preparation has an impact on the menarche experience in adolescents. Menarche is seen as a transitional period associated with religious and socio-cultural significance. The purpose of this review is to describe the menarche experience in adolescents. This review uses arksey \& O'Malley framework with 5 stages namely: identifying questions, identifying relevant articles, selecting articles, mapping charting data, compiling, summarizing and creating reports. The results of 6 literatures were selected with two themes that appeared, namely positive and negative attitudes and changes that occurred in adolescents with menarche.
\end{abstract}

Keywords: experience, menarche, adolescence

\section{INTRODUCTION}

Menarche (the first menstrual period) is a normal event in the period of growth and development in adolescent girls, (Ajong et al., 2020) which is a sign of physical maturity and fertility (Marván \& Molina-Abolnik, 2012). Menarche affects people's socio-cultural and religious life (Hawkey et al., 2017b) which is sometimes perceived as a negative thing (Siabani et al., 2018).

Preparation before menarche impacts adolescent experience (Marván \& MolinaAbolnik, 2012) which can affect both physical and psychological changes of adolescents (Mudey et al., 2010). Missinformation can affect emotional responses and adolescent attitudes and behaviors during menarche (Chandra-Mouli \& Patel, 2017a). Community responses related to menarche and menstruation are considered taboo and troubling, as a result when teenagers experience menarche will show negative emotions, attitudes and behaviors. (Rizkia et al., 2019b)

Indigenous peoples restrict youth by menarche to do activities without notifying. (Sachdeva \& Sharma, 2017). Teenagers follow stricter traditions, taht reproductive problems are a taboo issue to discuss. This affects adolescents who are supposed to menarche and menstruate as normal processes, turning into something that can threaten their mental physical health and adolescent psychology, both at school, at home and in the community (Lahme et al., 2018). 
Many teenagers do not have good care and support for their problems, making this experience a different perception in every teenager, and changing their daily lives. So it takes efforts to improve the needs of youth related to menarche both among the community, schools, and family(Chandra-Mouli \& Patel, 2017b).

\section{RESEARCH METHODS}

The methods used in scoping reviews with the Arksey \& O'Malley framework with 5 stages among others: (1) identifying Scoping review questions, (2) identifying relevant articles (3) selecting relevant articles using inclusion and exclusion criteria, (4) mapping charting data (5) compiling, summarizing and reporting review results.

\section{Step 1 : identify scoping review questions}

The question in this scoping review is "how does a teenager experience in the face of menarche?" to develop a focus of questions and search strategies on qualitative research. Use of PEOS (Population, Exposure, Outcome, Study design).

Tabel 1. Identifikasi unsur-unsur pertanyaan menggunakan PEOS

\begin{tabular}{llll}
\hline Population & Exposure & Outcome or Themes & Study design \\
\hline 1. Adolescent & 1. Menarche & Experience & Qualitative study \\
2. Teenagers & 2. First period & & \\
3. Young adults & 3. First menstruation & & \\
4. Teen & & & \\
5. Youth & & & \\
\hline
\end{tabular}

\section{Step 2 : identify relevant articles}

This literature uses databased including PubMed, ScienceDirect, and EBSCO, and uses grey literature. Keywords used "Experience Adolescent Menarche" then supported with additional keywords. In helping to describe the problem determined criteria of inclusion and exclusion.

Table 2. criteria for inclusion and exclusion

\begin{tabular}{lll}
\hline \multicolumn{1}{c}{ Inclusion criteria } & \multicolumn{1}{c}{ Exclusion criteria } \\
\hline $\begin{array}{l}\text { 1. Articles published between 2009- } \\
\text { 2019 }\end{array}$ & $\begin{array}{l}\text { 1. Opinion articles } \\
\text { 2. Articles in English and Indonesian review } \\
\text { 3. Primary research or riview article } \\
\text { published in a peer-reviewed }\end{array}$ & $\begin{array}{l}\text { 3. Articles with other than English } \\
\text { and Indonesian }\end{array}$ \\
$\begin{array}{l}\text { journal } \\
\text { 4. Articles discussing early menarche } \\
\text { factors } \\
\text { guideline of WHO / certain formal } \\
\text { organisations }\end{array}$ & \\
5. Arikel who explores the perception \\
$\begin{array}{l}\text { of adolescents towards menarche } \\
\text { Arikel who explores the impact of } \\
\text { menarche on adolescents }\end{array}$
\end{tabular}

\section{Step 3: article selection}

In the search for identified articles 674 articles, there were 371 articles that were duplicates, after being filtered for relevance obtained 88 articles. Then done filtering the article by selecting through the title and abstract there are 82 articles, then in the 
filtering by reading in its entirety about the experience of menarche in adolescents obtained 6 articles that will be used for Scoping Review.

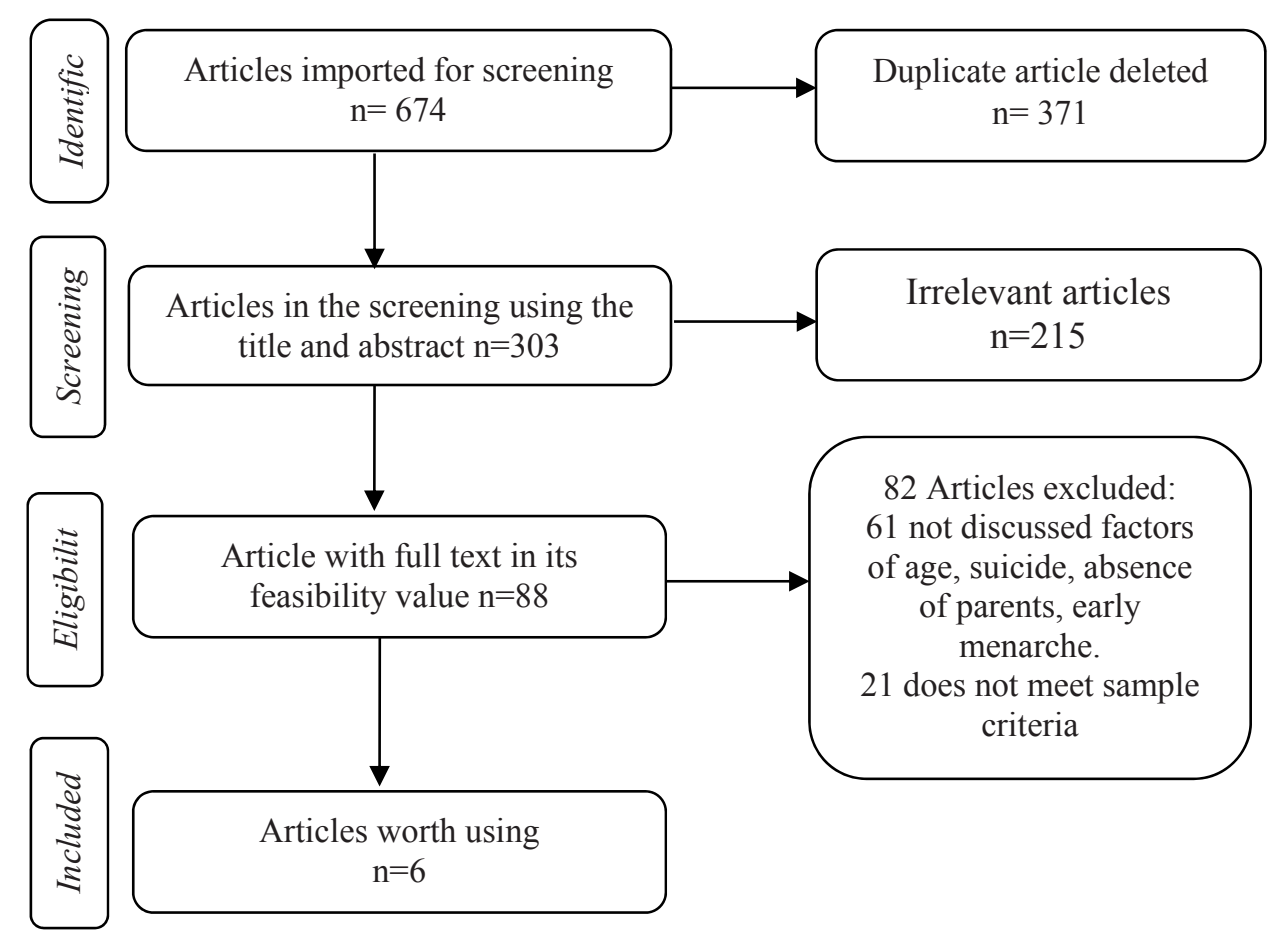

Figure 1. Prisma Flow Diagram Of Literature Search Process Flow

\section{Step 4: mapping charting data}

From 6 articles obtained, then some key criteria are entered for classifying such as research population, research objectives and significant results or recommendations. The author independently records the information or then compares the data extracted. 


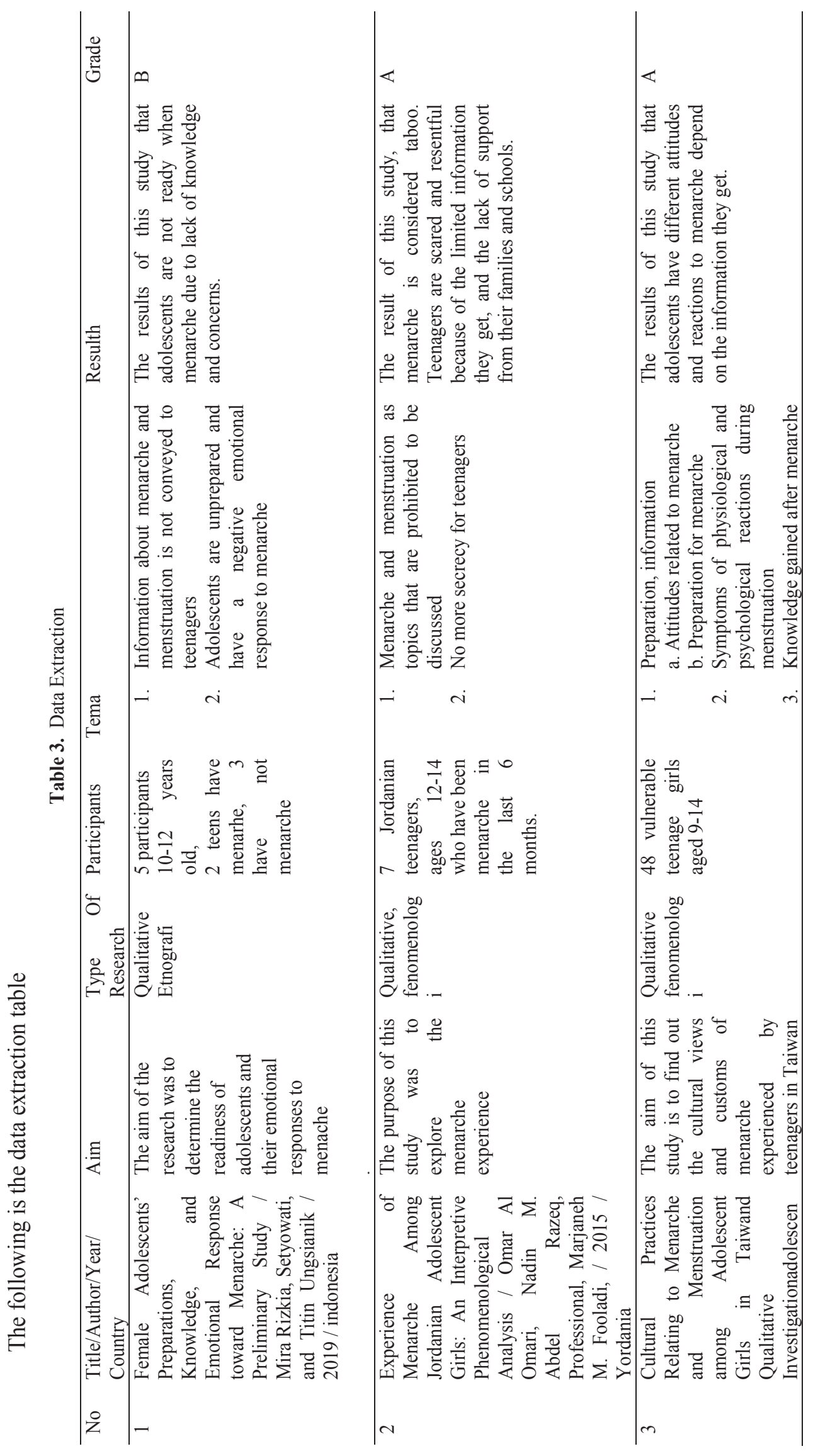




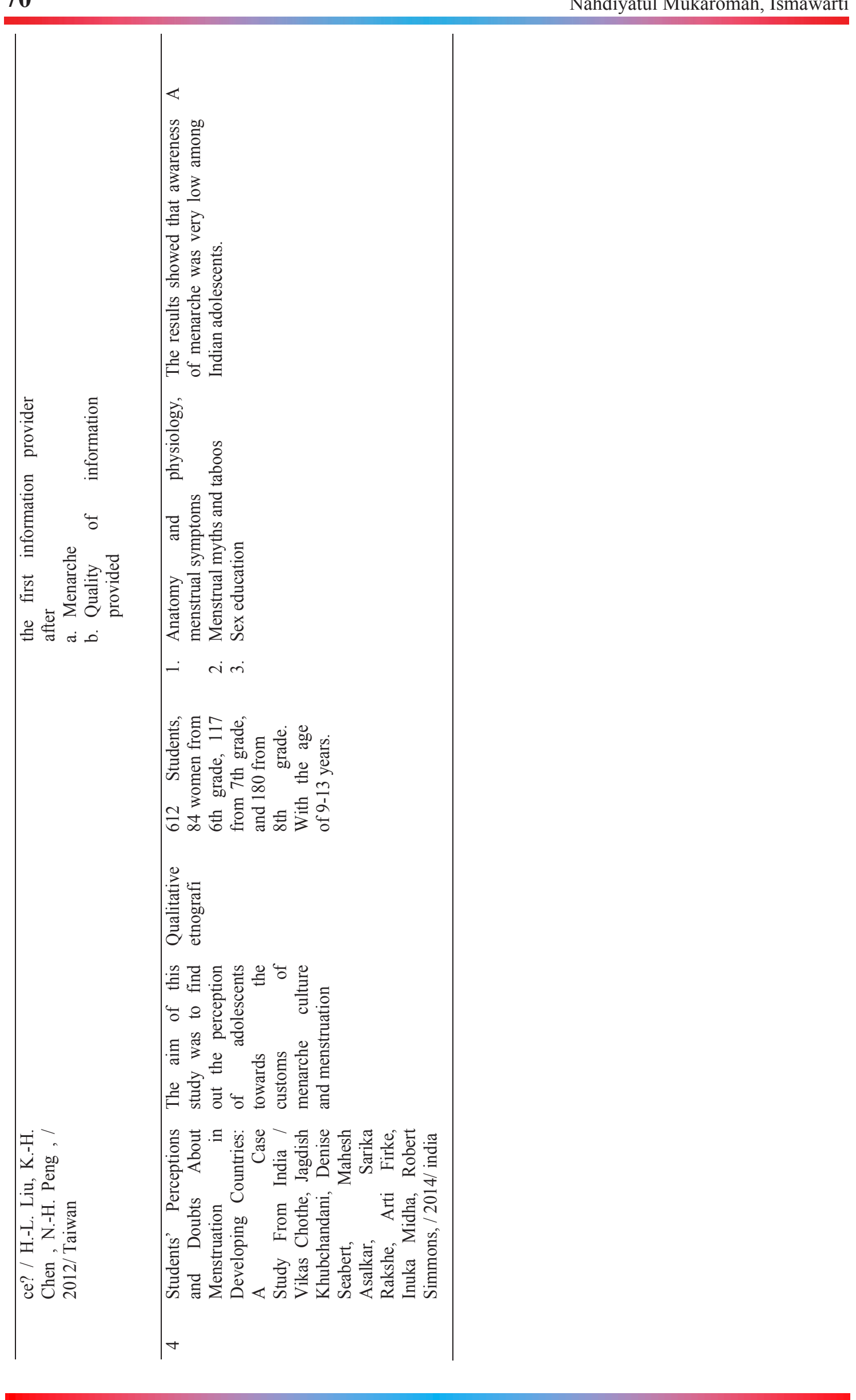

Nahdiyatul Mukaromah, Ismawarti 

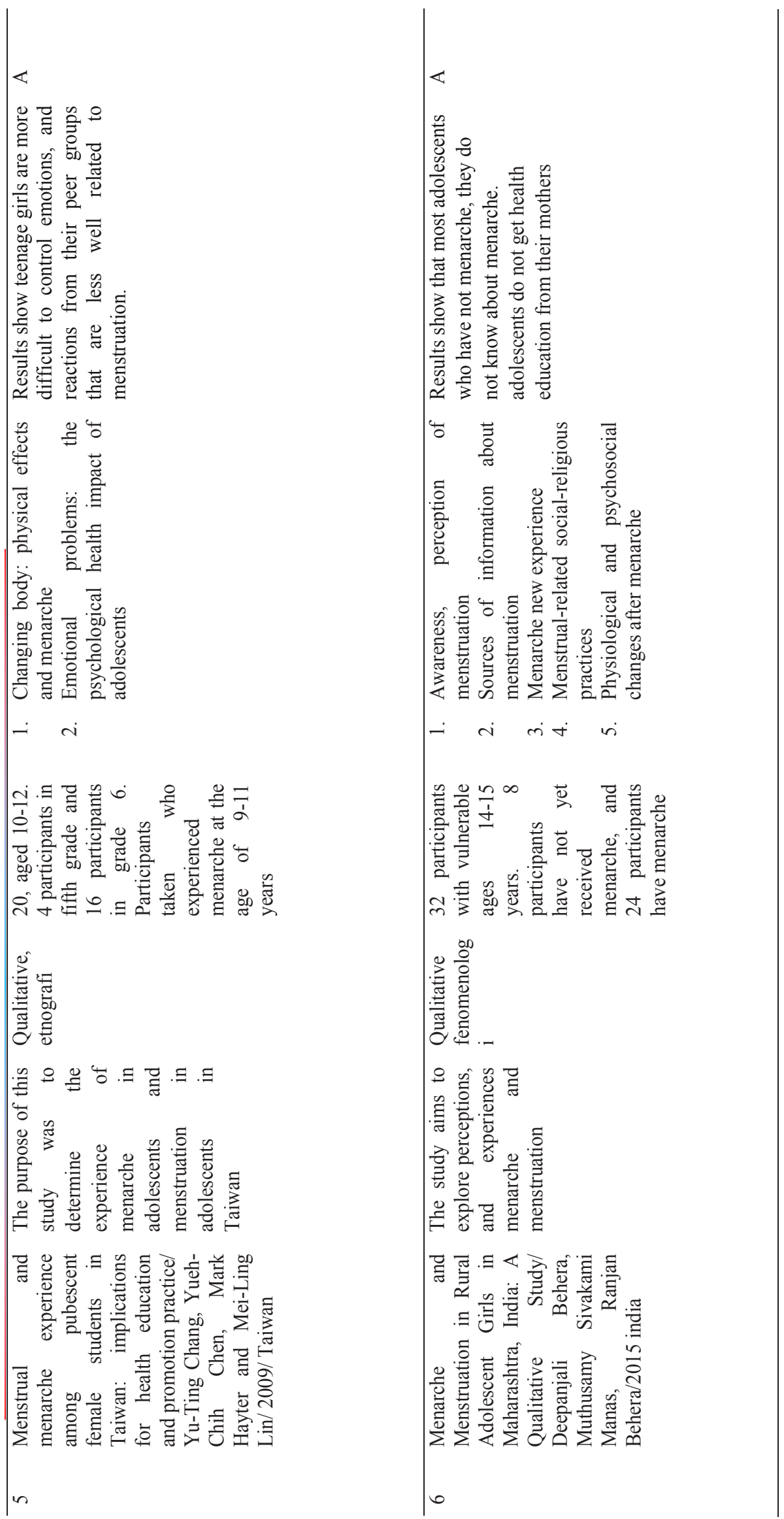


\section{Step 5: compiles, summarizes and reports the results of the review.}

Based on 6 articles that have been selected and in accordance with good quality, furthermore, data extraction is carried out to classify several points or parts of the article such as research objectives, research methods, samples and the results or findings of the research. In the article obtained this research was conducted in the country: 1 article from Indonesia, 1 article from Jordan, 2 articles from Taiwan, 2 articles from India selected articles with good quality with grades A and B.

In this mapping step the author classifies the interesting findings of the reviews in these articles

Table 4. mapping of article findings

\begin{tabular}{ll}
\hline Theme & Sub theme \\
\hline Adolescent attitude towards menarche & 1. Positive reception ${ }^{1,2,3,5,6}$ \\
& 2. Negative reception ${ }^{1,2,3,5}$ \\
\hline Changes that occur in adolescents by & $\begin{array}{l}\text { 1. Physiological } \\
\text { menarche }\end{array}$ \\
& 2. Psychological ${ }^{3,5}$ \\
& 3. Socio-cultural \\
&
\end{tabular}

Description : number is the article code on the charting data

\section{RESULTS AND DISCUSSION}

This Scoping Review identifies 6 relevant publications drawn from the last 10 years of limited sources involving menarche attitudes, and menarche impacts. The findings show:

1. Adolescent attitude towards menarche

a. Positive reception

That research conducted in Taiwan, some teenagers consider menarche as a natural thing, and a feeling of pleasure because it feels grown up.(H.-L. Liu et al., 2012); (Behera et al., 2015). Menstruation can be seen as more than just a physiological process. This can be seen positively by the community. The positive perception of menstruation is to judge as a sign of femininity, fertility. (Ali \& Rizvi, 2010). According to research (Chang \& Lin, 2013) shows that adolescents who have experienced menarche perceive it as something to be happy because of sexual changes and maturity of reproductive abilities so that they grow into mature women and can be responsible for themselves.

b. Negative reception

The findings of some journals say that more than half of adolescents consider menarche to be a negative thing such as fear, anxiety, or having strange feelings, and bad feeling. (Al Omari et al., 2016). There is a sense of worry when facing menarche and a feeling of shame because of taboos when discussing reproductive system problems (Rizkia et al., 2019a) and should not be discussed and kept secret. (Jackson, 2013).

The study reported the presence of women who were not ready for their first menstruation due to lack of knowledge. (do Amaral et al., 2011). Limited information obtained related to the customs and social culture in society makes teenagers be negative and not ready to face menarche, as well as can improve poor personal hygiene during menstruation. (Hawkey et al., 2017a).

2. Changes that occur in adolescents by menarche 
a. Physiological

Some studies suggest that participants felt physical changes that occurred after menarche. Changes in body shape include, breast, increased body width, weight gain, the appearance of acne on the face, pain in the abdomen and back when menarche. (Behera et al., 2015); (Chothe et al., 2014); (Chang et al., 2009). In a study conducted in Nagpur, India, that adolescents when menarche and menstruation experience abdominal pain and back pain, headaches and and cramps in the legs. Abdominal cramping pain Fatigue and mood swings. It's also a problem most often felt in adolescents when menarche and menstruation (Sachdeva \& Sharma, 2017).

b. Psychological

There are emotional and mood changes occurring during menarche and menstruation. teenagers sometimes feel sad and irritable in the days before or after menstruation. While other participants explained that they were more irritable or cried more than usual (Chang et al., 2009) and feel irritable, bad heart and mood swings. (H. L. Liu et al., 2012). Sometimes it's followed by anxiety. (Shanbhag et al., 2012). Changes in emotional problems are associated with hormonal changes in adolescents. (Chang et al., 2009) .

c. Socio-cultural

Sometimes teenagers feel confused about the reasons behind cultural and social restrictions for women who get menstruation done in the family. Some participants also did not go to school, avoided dance classes, cut back on outdoor games, and did not visit temples, and did not do daily work (Chothe et al., 2014) (Gultie et al., 2014). The same is practiced by their parents, due to unconceptions and misperceptions about menarche and menstruation. Customary and cultural restrictions for young people who are menarche and construct more on rural youth compared to urban areas, this difference is due to the inherent stigma of rural communities and lack of knowledge in rural communities (Omidvar \& Begum, 2010)(Mudey et al., 2010).

The same was found by (Al Omari et al., 2016) in Jordan that menarche changed the lives of teenage girls abruptly, because it changed the social and religious order. Teenagers who are menstruating are should not visit holy places (mosques) and from fasting, praying, or touching the scriptures. According to research (Behera et al., 2015) Teenagers are forbidden to worship god, cook and do homework. According to research (McMahon et al., 2011) in Kenya that the prohibition of doing housework for women by menarche as a form of mechanism rules to maintain cleanliness at home.

\section{CONCLUSION}

Adolescence leading into the adult phase is characterized by physical changes, sexual maturity, psychosocial changes. In this phase, adolescents experience the first menstruation that causes a lack of anxiety, worry, and perception. Teenagers do not get information, sexual education and reproduction, because this is considered a taboo that should not be discussed among schools, families and communities. This causes mental distress in adolescents. (Shanbhag et al., 2012). Adolescents who go through puberty are particularly vulnerable to socio-cultural influences. Therefore, an understanding of 
topics such as menstruation has social and cultural power. It is necessary to provide health education so that it can affect the knowledge, application, understanding of adolescents towards menstruation. (Chang \& Lin, 2013)

Too many adolescents do not know about menarche and about normal biological maturation as well as normal changes that occur in adolescents. Teenagers who get a good menarche education should also strive to get good personal hygiene, as well as physical and emotional support from the surrounding environment(Chandra-Mouli \& Patel, 2017b)

There needs to be efforts to step up and apply well in supporting adolescent knowledge related to menarche and personal hygiene. Girls and boys need to be educated about puberty, so they can support from the surrounding environment including family(Chandra-Mouli \& Patel, 2017b). Although menstruation attitude is good, but the knowledge of hygiene is still lacking, so health services and health education provide programs about menarche and menstruation both in school and college(Siabani et al., 2018).

The need for school health services preventive efforts for all students and students. (Moodi, Shahnazi, Sharifirad, \& Zamanipour, 2013). In 2014, UNESCO published a policy manual to improve the ability of teachers as educators and support boys and girls while in school (UNICEF, 2014). Because inadequate and inappropriate education can be a problem in the family related to reproductive problems in adolescents. Parents, teachers, and health workers in schools should be aware of this and be responsible for teaching menstrual topics to adolescents. (Chang \& Lin, 2013).

\section{REFERENCES}

Ajong, A. B., Tankala, N. N., Yakum, M. N., Azenoi, I. S., \& Kenfack, B. (2020). Knowledge of peri-menarcheal changes and a comparative analysis of the age at menarche among young adolescent school girls in urban and rural Cameroon. 110.

Al Omari, O., Abdel Razeq, N. M., \& Fooladi, M. M. (2016). Experience of Menarche Among Jordanian Adolescent Girls: An Interpretive Phenomenological Analysis. Journal of Pediatric and Adolescent Gynecology, 29(3), 246-251. https://doi.org/10.1016/j.jpag.2015.09.005

Ali, T. S., \& Rizvi, S. N. (2010). Menstrual knowledge and practices of female adolescents in urban Karachi, Pakistan. Journal of Adolescence, 33(4), 531-541. https://doi.org/10.1016/j.adolescence.2009.05.013

Behera, D., Sivakami, M., \& Behera, M. R. (2015). Menarche and Menstruation in Rural Adolescent Girls in Maharashtra, India: A Qualitative Study. Journal of Health Management, 17(4), 510-519. https://doi.org/10.1177/0972063415612581

Chandra-Mouli, V., \& Patel, S. V. (2017a). Mapping the knowledge and understanding of menarche, menstrual hygiene and menstrual health among adolescent girls in low- and middle-income countries. In Reproductive Health (Vol. 14, Issue 1). BioMed Central Ltd. https://doi.org/10.1186/s12978-017-0293-6

Chandra-Mouli, V., \& Patel, S. V. (2017b). Mapping the knowledge and understanding of menarche, menstrual hygiene and menstrual health among adolescent girls in low- and middle-income countries. Reproductive Health, 14(1), 30. https://doi.org/10.1186/s12978-017-0293-6

Chang, Y. T., Chen, Y. C., Hayter, M., \& Lin, M. L. (2009). Menstrual and menarche 
experience among pubescent female students in Taiwan: Implications for health education and promotion practice. Journal of Clinical Nursing, 18(14), 2040-2048. https://doi.org/10.1111/j.1365-2702.2008.02545.x

Chang, Y. T., \& Lin, M. L. (2013). Menarche and menstruation through the eyes of pubescent students in Eastern Taiwan: Implications in sociocultural influence and gender differences issues. Journal of Nursing Research, 21(1), 10-18. https://doi.org/10.1097/jnr.0b013e3182829b26

Chothe, V., Khubchandani, J., Seabert, D., Asalkar, M., Rakshe, S., Firke, A., Midha, I., \& Simmons, R. (2014). Students' Perceptions and Doubts About Menstruation in Developing Countries: A Case Study From India. Health Promotion Practice, 15(3), 319-326. https://doi.org/10.1177/1524839914525175

do Amaral, M. C. E., Hardy, E., \& Hebling, E. M. (2011). Menarche among Brazilian women: Memories of experiences. Midwifery, 27(2), 203-208. https://doi.org/10.1016/j.midw.2009.05.008

Gultie, T., Hailu, D., \& Workineh, Y. (2014). Age of menarche and knowledge about menstrual hygiene management among adolescent school girls in Amhara province, Ethiopia: implication to health care workers \& school teachers. PloS One, 9(9), e108644. https://doi.org/10.1371/journal.pone.0108644

Hawkey, A. J., Ussher, J. M., Perz, J., \& Metusela, C. (2017a). Experiences and Constructions of Menarche and Menstruation among Migrant and Refugee Women. Qualitative Health Research, 27(10), 1473-1490. https://doi.org/10.1177/1049732316672639

Hawkey, A. J., Ussher, J. M., Perz, J., \& Metusela, C. (2017b). Experiences and Constructions of Menarche and Menstruation Among Migrant and Refugee Women. Qualitative Health Research, 27(10), 1473-1490. https://doi.org/10.1177/1049732316672639

Jackson, T. E. (2013). Women wearing white: Discourses of menstruation and the experience of menarche. https://doi.org/10.1177/0959353512473812

Lahme, A. M., Stern, R., \& Cooper, D. (2018). Factors impacting on menstrual hygiene and their implications for health promotion. Global Health Promotion, 25(1), 5462. https://doi.org/10.1177/1757975916648301

Liu, H.-L., Chen, K.-H., \& Peng, N.-H. (2012). Cultural practices relating to menarche and menstruation among adolescent girls in Taiwan--qualitative investigation. Journal of Pediatric and Adolescent Gynecology, 25(1), 43-47. https://doi.org/10.1016/j.jpag.2011.08.006

Liu, H. L., Chen, K. H., \& Peng, N. H. (2012). Cultural Practices Relating to Menarche and Menstruation among Adolescent Girls in Taiwan-Qualitative Investigation. Journal of Pediatric and Adolescent Gynecology, 25(1), 43-47. https://doi.org/10.1016/j.jpag.2011.08.006

Marván, M. L., \& Molina-Abolnik, M. (2012). Mexican Adolescents' Experience of Menarche and Attitudes Toward Menstruation: Role of Communication Between Mothers and Daughters. Journal of Pediatric and Adolescent Gynecology, 25(6), 358-363. https://doi.org/10.1016/j.jpag.2012.05.003

McMahon, S. A., Winch, P. J., Caruso, B. A., Ogutu, E. A., Ochari, I. A., \& Rheingans, R. D. (2011). "The girl with her period is the one to hang her head" Reflections on menstrual management among schoolgirls in rural Kenya. BMC International 
Health and Human Rights, 11(1). https://doi.org/10.1186/1472-698X-11-7

Mudey, A. B., Kesharwani, N., Mudey, G. A., \& Goyal, R. C. (2010). A Cross-sectional Study on Awareness Regarding Safe and Hygienic Practices amongst School Going Adolescent Girls in Rural Area of Wardha District, India. Global Journal of Health Science, 2(2), 225-231. https://doi.org/10.5539/gjhs.v2n2p225

Omidvar, S., \& Begum, K. (2010). Factors influencing hygienic practices during menses among girls from south India- A cross sectional study. International Journal of Collaborative Research on Internal Medicine and Public Health, 2(12), 411-423.

Rizkia, M., Setyowati, \& Ungsianik, T. (2019a). Female Adolescents' Preparations, Knowledge, and Emotional Response toward Menarche: A Preliminary Study. Comprehensive Child and Adolescent Nursing, 42(sup1), 108-114. https://doi.org/10.1080/24694193.2019.1578431

Rizkia, M., Setyowati, \& Ungsianik, T. (2019b). Female Adolescents' Preparations, Knowledge, and Emotional Response toward Menarche: A Preliminary Study. Comprehensive Child and Adolescent Nursing, 42(sup1), 108-114. https://doi.org/10.1080/24694193.2019.1578431

Sachdeva, A., \& Sharma, S. (2017). Original Research Article KNOWLEDGE ABOUT MENSTRUAL PROBLEMS AND MENSTRUAL HYGIENE PRACTICES AMONG COLLEGE GOING UNMARRIED GIRLS IN CHANDIGARH , INDIA Original Research Article. 4(67), 4019-4025. https://doi.org/10.18410/jebmh/2017/803

Shanbhag, D., Shilpa, R., D’Souza, N., Josephine, P., Singh, J., \& Goud, B. R. (2012). Perceptions regarding menstruation and practices during menstrual cycles among high school going adolescent girls in resource limited settings around Bangalore city, Karnataka, India. International Journal of Collaborative Research on Internal Medicine and Public Health, 4(7), 1353-1362.

Siabani, S., Charehjow, H., \& Babakhani, M. (2018). Knowledge, Attitudes and Practices ( KAP) Regarding Menstruation among School Girls in West of Iran : A Population Based Cross-Sectional Study. 6(56), 8075-8085. https://doi.org/10.22038/ijp.2018.28633.2495 